\title{
Characteristics of Geriatric Health Service Facilities Designated as Sites of Death
}

\author{
Mitsumi Ono $^{1^{*}}$, Hideyuki Kanda ${ }^{2}$, Yuko Takeda ${ }^{1}$, Sachiko Hara ${ }^{1}$ \\ ${ }^{1}$ Department of Community Health and Gerontological Nursing, Faculty of Medicine, \\ Shimane University, Izumo, Japan \\ ${ }^{2}$ Department of Environmental Medicine and Public Health, Faculty of Medicine, \\ Shimane University, Izumo, Japan

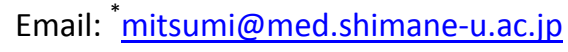

Received 27 August 2015; accepted 12 October 2015; published 15 October 2015

Copyright (C) 2015 by authors and Scientific Research Publishing Inc.

This work is licensed under the Creative Commons Attribution International License (CC BY). http://creativecommons.org/licenses/by/4.0/

\section{(c) (i) Open Access}

\section{Abstract}

There are many deaths occurring among the aged population in Japan. Geriatric Health Service Facilities (GHSFs) are highlighted as some of the chosen facilities designated as sites of death. The aim of our study was to clarify the characteristics and related factors, including physical signs first noticed by staff at the end-of-life period, in GHSFs designated as sites of death, using a nationwide survey in Japan. We administered a questionnaire to 3971 GHSFs in Japan. Eligible responses for the study were obtained from 854 GHSFs. We found that GHSFs designated as sites of death were more likely to have basic policies and documented preferences regarding end-of-life care. We also found that staff members in GHSFs designated as sites of death were less likely to first notice physical signs of pain. We found that GHSFs designated as sites of death tended to identify earlier symptoms, such as reduced oral intake and less vigor. Our results would enable elderly persons, their families, and staff in GHSFs to prepare for the elderly's death more efficiently though earlier identification of the end-of-life period. We hope that GHSFs have an important role to play in end-of-life care provision to elderly persons in Japan, through the strengthening of these intermediate facilities.

\section{Keywords}

Geriatric Health Service Facility, End-of-Life Care, Basic Policy, Preference Documented, Physical Signs

\footnotetext{
${ }^{*}$ Corresponding author.
} 


\section{Introduction}

There are many deaths occurring among the elderly population in Japan. The death rate is estimated to reach 1.67 million people per year in 2040 [1]. Most elderly persons die after undergoing prolonged medical and nursing care. In order to appropriately deal with nursing care issues peculiar to aging societies, the ling-term care insurance system started in April 2000 so that people who need nursing care can get enough social support [2]. The long-term care insurance system gives those in need of long-term care due to a disease caused by an old age or for other reasons necessary services in a comprehensive and uniform way so that they can lead an independent life as much as possible. It is the user-oriented system where you can use the service you choose yourself. After its launch, there was a fast increase in the use of nursing care. Now, the long-term care insurance system has come to have an important role as a system to assure a comfortable life for elderly persons and their family members. The long-term care insurance facilities are facility services based on this insurance. Elderly persons have death under nursing care for long time. Persons receiving facilities services can have possibilities to face death in facilities, not in hospitals. Thus, those facilities will be utilized as the places with sites of death in near future.

Geriatric Health Service Facilities (GHSFs) offer physical therapy to elderly people, to support their everyday living functions and provide other assistance, so that they can resume independent living at home [3]. Since the goal is to return elderly people to home life, periodic checks are conducted to determine whether these individuals can return home. Depending on the nature of the illness, facilities introduce an appropriate medical institution, if hospital treatment is considered necessary. GHSFs also admit elderly people on a short-term basis, to support their living at home. Thus, the role played by GHSFs is that of "intermediate" facilities, that is, facilities with multiple functions, including functioning as hospitals or other facilities and home, or providing in-home nursing care. These facilities are some of those considered helpful in the provision of the long-term care support in familiar environments within the comprehensive care system in Japan [4]. In 2009, the Japanese government established the nursing care benefit for site-of-death care at GHSFs and revised the terms of the long-term care insurance [5]. They also play a role in end-of-life care. Then, both the nursing care benefit for site-of-death care and assessment were improved with revision in 2012, so as to promote end-of-life care in GHSFs [6].

Japan Association of GHSFs has stated that more than half of GHSFs can provide end-of-life care [7]. However, previous studies have reported the difficulties associated with GHSFs as places of death, due to the inadequacies of both the environment and the system, and the lack of pain control [8]-[10]. According to a report, approximately $30 \%$ of facilities sent elderly persons to hospitals, even if the elderly persons concerned and their families approved of end-of-life care in nursing homes [11]. The physical signs first noticed by staff at the end-of-life period are not well known in GHSFs. Most previous studies on end-of-life care in GHSFs targeted facilities designated as sites of death only. There are few studies involving a comparison of GHSFs designated as sites of death and those not designated.

The aim of our study is to clarify the characteristics of and related factors in GHSFs, including the end-of-life physical signs noticed by staff at these facilities, through a nationwide survey in Japan. Our results will not only promote GHSFs as sites of death, but also suggest the role that can be possibly played by the facilities in end-oflife care within a comprehensive care system.

\section{Subjects and Methods}

\subsection{Subjects}

The subjects were 3971 GHSFs registered on the Long-term Care Insurance Services Informational Publication System, adopted by all the prefectures in Japan, as at January 2015. For our survey, we requested the cooperation of the medical managers, such as nursing administrators, and sent the questionnaires to the 3971 GHSFs. There were a total of 1032 responses from those GHSFs. Of the 1032 respondents, 7 did not give informed consent and 171 did not give the complete data needed for analysis, such as missing and invalid responses. On the basis of these rejection criteria, 854 eligible responses remained in the study: 21.5\% (854/3971) of all subjects and $82.8 \%$ (854/1032) of the feedback data (Figure 1).

\subsection{Questionnaire}

The questionnaire consisted of the following three parts: characteristics of the facilities, procedures relating to 


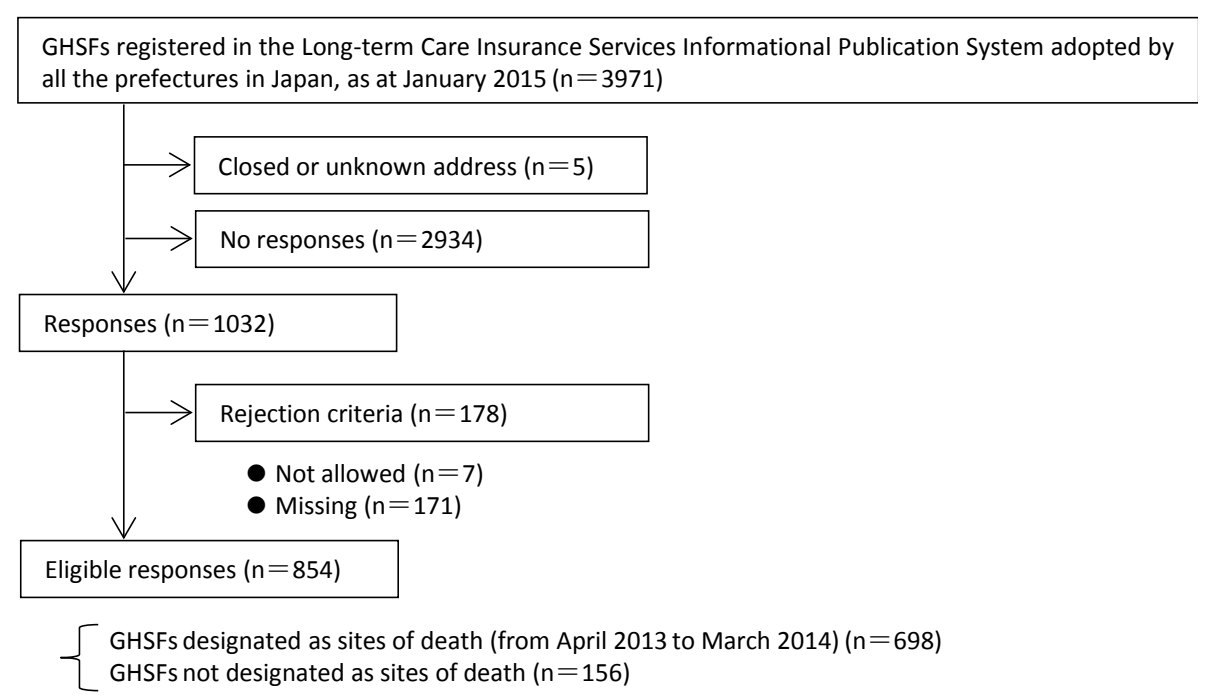

Figure 1. Study procedures. GHSF: Geriatric health service facility.

the site of death in the GHSFs and physical signs which most staff members noticed first among end-of-life residents.

We sent the questionnaires to the relevant facilities from the end of January to the beginning of February, in 2015. The questionnaires were handed to the medical managers for anonymous completion. The completed questionnaires were returned to our researchers until the end of March 2015.

The contents of the survey included the characteristics of the facilities [presence of branches of medical institutions (hospital, clinic with beds, and clinic without beds), provision of other services to elderly persons, the number of beds in facilities, the average care-need level, the average home return rate, and location of facilities]. We also asked about the procedures relating to the site of death in the GHSFs (whether the facility has a basic policy on end-of-life care or not, whether there is a preference for individuals to have a documented living will or not). The facilities were asked about the number of residents who had died therein within the past year (from April 2013 to March 2014). Then, we obtained information on physical signs, which most staff members noticed first among end-of-life residents—reduced oral intake, sleepiness during daytime, less vigor, oliguria, dyspnea, edema, and complaints of pain.

All the procedures of this study were reviewed and approved by the Institution Review Board of Shimane University Faculty of Medicine (No. 241, Approved on $19^{\text {th }}$ January, 2015).

\subsection{Statistical Analysis}

GHSFs designated as sites of death were defined as facilities in which at least one death had occurred within the past year. Student t-tests and $\chi^{2}$ tests were used to compare the proportion of GHSFs designated as sites of death and those not designated. A multiple logistic regression analysis was used to assess the contribution of each independent variable, including characteristics and physical signs, towards GHSFs designated as sites of death.

The Statistical Package for the Social Sciences (SPSS JAPAN Inc., version 19.0J, Tokyo, Japan) was used for the analyses. All probability values were two-tailed and all confidence intervals were estimated at the $95 \%$ level.

\section{Results}

Table 1 shows the characteristics of GHSFs designated as sites of death and those not designated. There were fewer standard types of GHSFs under the notification system in the long-term care insurance, in GHSFs designated as sites of death than in those not designated. There were many more clinics without beds, which were either primary or affiliate institutes of medical care, in GHSFs designated as sites of death than in those not designated. GHSFs designated as sites of death were slightly more independent of medical institutions than were those not designated. Moreover, both basic policies on end-of-life care and documented preferences in the form of a living will were more common in GHSFs designated as sites of death. The average level of care needs in 
Table 1. The characteristics of GHSFs designated as sites of death and those not designated.

\begin{tabular}{|c|c|c|c|c|c|}
\hline \multirow[b]{2}{*}{ Notification facilities: standard type (number, \%) } & \multicolumn{2}{|c|}{$\begin{array}{c}\text { GHSFs designated as sites of } \\
\text { death }(n=698)\end{array}$} & \multicolumn{2}{|c|}{$\begin{array}{l}\text { GHSFs not designated } \\
(\mathrm{n}=156)\end{array}$} & \multirow{2}{*}{$\begin{array}{r}\boldsymbol{p} \text {-value } \\
0.04\end{array}$} \\
\hline & 456 & $(94.0)$ & 153 & $(98.1)$ & \\
\hline \multicolumn{6}{|l|}{ Primary or affiliate medical institutes (number, \%) } \\
\hline Hospital & 421 & $(60.3)$ & 99 & $(63.5)$ & 0.47 \\
\hline Clinic with beds & 67 & $(9.6)$ & 9 & $(5.8)$ & 0.13 \\
\hline Clinic without beds & 110 & $(15.8)$ & 10 & $(6.4)$ & $<0.01$ \\
\hline Independence & 127 & $(18.2)$ & 43 & $(27.6)$ & $<0.01$ \\
\hline \multicolumn{6}{|l|}{ Other services for elderly persons (number, \%) } \\
\hline Day-care & 612 & $(87.7)$ & 131 & $(84.0)$ & 0.21 \\
\hline Short-stay & 492 & $(70.5)$ & 116 & $(74.4)$ & 0.33 \\
\hline In-home care management office & 432 & $(61.9)$ & 104 & $(66.7)$ & 0.27 \\
\hline \multicolumn{6}{|l|}{ Location (number, \%) } \\
\hline Hokkaido·Tohoku & 121 & $(17.3)$ & 34 & $(21.8)$ & 0.08 \\
\hline Kanto·Koushinetsu & 195 & $(27.9)$ & 46 & $(29.5)$ & \\
\hline Hokuriku·Tokai & 92 & $(13.2)$ & 18 & $(11.5)$ & \\
\hline Kinki & 95 & $(13.6)$ & 22 & $(14.1)$ & \\
\hline Chugoku·Shikoku & 113 & $(16.2)$ & 22 & $(14.1)$ & \\
\hline Kyusyu·Okinawa & 82 & $(11.8)$ & 14 & $(9.0)$ & \\
\hline Basic policy on end-of-life care (number, \%) & 562 & $(80.5)$ & 41 & $(26.3)$ & $<0.01$ \\
\hline \multirow[t]{2}{*}{ Preference documented (number, \%) } & 533 & $(76.4)$ & 51 & $(32.7)$ & $<0.01$ \\
\hline & & & & & $p$-value ${ }^{b}$ \\
\hline Number of beds (number, $\mathrm{M} \pm \mathrm{SD}$ ) & $92.8 \pm 29.2$ & & $90.05 \pm 30.62$ & & 0.23 \\
\hline Average care-need levels (level, $\mathrm{M} \pm \mathrm{SD}$ ) & $3.3 \pm 0.4$ & & $3.23 \pm 0.36$ & & 0.04 \\
\hline Average return-to-home rates $(\%, \mathrm{M} \pm \mathrm{SD}$ ) & $24.9 \pm 21.4$ & & $23.75 \pm 17.98$ & & 0.53 \\
\hline $\begin{array}{l}\text { Average number of deaths at the facilities } \\
\text { (people, } \mathrm{M} \pm \mathrm{SD} \text { ) }\end{array}$ & $9.1 \pm 8.5$ & & & & \\
\hline
\end{tabular}

${ }^{\mathrm{a}} p$-value for $\chi^{2}$ test; ${ }^{\mathrm{b}} p$-value for t-test; GHSF: Geriatric Health Service Facility.

GHSFs designated as sites of death was higher than that of those not designated. The average number of deaths in GHSFs designated as sites of death was $9.1 \pm 8.5$.

Table 2 shows the physical signs that most staff members noticed first at the end-of-life period among residents at GHSFs designated as sites of death and those not designated. The proportions of "reduced oral intake", "sleepiness during daytime", and "less vigor" were higher in GHSFs designated as sites of death than among those not designated, and "reduced oral intake" and "sleepiness during daytime" had statistically significance. On the other hand, the proportions of "oliguria", "dyspnea”, "edema”, and "complaints of pain" were lower in GHSFs designated as sites of death; statistical significance was obtained for "dyspnea" and "complaints of pain."

Table 3 shows the odds ratios and 95\% confidence intervals for GHSFs designated as sites of death, determined using multiple logistic regression analysis. Both basic policies and preferences documented at end-of-life care facilities were positively associated with GHSFs designated as sites of death. "Complaints of pain", as a physical sign noticed first by most staff members at the end-of-life period, was negatively associated. We also 
Table 2. End-of-life physical signs noticed first by most staff members among residents of GHSFs designated as sites of death and those not designated.

\begin{tabular}{|c|c|c|c|c|c|}
\hline \multirow[b]{2}{*}{ Reduced oral intake (number, \%) } & \multicolumn{2}{|c|}{$\begin{array}{c}\text { GHSFs designated } \\
\text { as sites of death }(n=698)\end{array}$} & \multicolumn{2}{|c|}{$\begin{array}{l}\text { GHSFs not designated } \\
\qquad(\mathrm{n}=156)\end{array}$} & \multirow{2}{*}{$\begin{array}{c}\boldsymbol{p} \text {-value } \\
0.02\end{array}$} \\
\hline & 646 & $(92.6)$ & 135 & $(86.5)$ & \\
\hline Sleepiness during daytime (number, \%) & 512 & $(73.4)$ & 101 & $(64.7)$ & 0.03 \\
\hline Less vigor (number, \%) & 350 & $(50.1)$ & 74 & $(47.4)$ & 0.54 \\
\hline Oliguria (number, \%) & 486 & $(69.6)$ & 117 & $(75.0)$ & 0.18 \\
\hline Dyspnea (number, \%) & 341 & $(48.9)$ & 100 & $(64.1)$ & $<0.01$ \\
\hline Edema (number, \%) & 278 & $(39.8)$ & 72 & $(46.2)$ & 0.15 \\
\hline Complaints of pain (number, \%) & 41 & $(5.9)$ & 20 & $(12.8)$ & $<0.01$ \\
\hline
\end{tabular}

$p$-value for $\chi^{2}$ test; GHSF: Geriatric Health Service Facility.

Table 3. The odds ratios and 95\% confidence intervals for the GHSFs designated as sites of death, determined using multiple logistic regression analysis.

\begin{tabular}{|c|c|c|}
\hline Variables & OR & $95 \% \mathrm{Cl}$ \\
\hline \multicolumn{3}{|l|}{ Characteristics } \\
\hline Basic policy on end-of-life care $(0=$ no, $1=$ yes $)$ & 6.79 & 4.23 to 10.90 \\
\hline Preference documented $(0=$ no, $1=$ yes $)$ & 2.63 & 1.66 to 4.17 \\
\hline Average care-need levels (+1 level) & 1.17 & 0.68 to 2.01 \\
\hline \multicolumn{3}{|l|}{ Primary or affiliate medical institutes } \\
\hline Clinic without beds $(0=$ no, 1 = yes $)$ & 1.53 & 0.72 to 3.27 \\
\hline Independence (0 = no, 1 = yes) & 0.81 & 0.50 to 1.33 \\
\hline Standard-type notification facilities ( $0=$ no, $1=$ yes $)$ & 0.31 & 0.83 to 1.16 \\
\hline \multicolumn{3}{|l|}{ Physical signs } \\
\hline Complaints of pain ( 0 = no, 1 = yes $)$ & 0.49 & 0.24 to 0.995 \\
\hline Dyspnea $(0$ = no, 1 = yes $)$ & 0.72 & 0.47 to 1.12 \\
\hline Reduced oral intake ( 0 = no, $1=$ yes $)$ & 1.21 & 0.63 to 2.32 \\
\hline Sleepiness during daytime $(0=$ no, $1=$ yes $)$ & 1.35 & 0.86 to 2.13 \\
\hline
\end{tabular}

CI: Confidence Intervals; GHSF: Geriatric Health Service Facility.

observed that GHSFs designated as sites of death had positive relationships with "clinic as primary medical institutions”, “average care-need level”, “sleepiness during daytime”, and "reduced oral intake”, which most staff members noticed at the end-of-life period among residents; however, none of the relationships reached statistical significance. We also found that GHSFs designated as sites of death had negative relations with "independence from medical institutions", "standard type of GHSF under the notification system in the long-term care insurance”, and “dyspnea”. Consequently, the characteristics of GHSFs designated as sites of death had more basic policies relating to end-of-life care and to documented preferences in the form of a living will. There were fewer "complaints of pain", as a physical sign first noticed by most staff members at the end-of-life period, in GHSFs designated as sites of death.

\section{Discussion}

We clarified the characteristics and physical signs of sites of death in GHSFs through a nationwide survey in Japan. We found that GHSFs designated as sites of death were more likely to have basic policies and documented preferences regarding end-of-life care than those not designated. We also found that GHSFs designated 
as sites of death had fewer physical signs of pain noticed first by most staff members at the end-of-life period in GHSFs designated as sites of death than those not designated.

GHSFs play the role of an "intermediate" facility for elderly persons who have difficulties going directly back home after being discharged from hospital. These individuals have the functions to resume activities of daily life and to support daily-life care at home. GHSFs support the lives of elderly people and their families through provision of both home and facility services when such care is needed. Often, the relationships between elderly people, their family members, and staff members at the facilities develop over time. Therefore, in end-of-life care, GHSFs also assume the role of satisfying families' requests regarding residence in the facilities and staff members' wishes to maintain care until individuals reach the sites of death [8] [12]. In 2009, the Japanese government set site-of-death care costs in GHSFs, with revision of the nursing-care benefit, to promote sites of death other than hospitals [5]. Then, with revision in 2012, the nursing care benefit for site-of-death care was further improved, so as to promote end-of-life care in GHSFs [6]. However, in 2013, the rate of deaths in GHSFs still made up 1.9\% of all deaths in Japan [13]. Clarifying the factors associated with the sites of death in GHSFs, with the exception of hospitals, would help promote end-of-life care. Ikegami et al. have reported factors related to end-of-life care in nursing homes, using nationwide surveys [14]. There are few studies in Japan on factors associated with end-of-life care in GHSFs, using a nationwide survey. In our knowledge, this is the first study on end-of-life care in GHSFs, using a national survey.

Our results showed that GHSFs designated as sites of death were more likely to have basic policies on endof-life care. A previous study also found that nursing homes with sites of death had statistically more basic policies on end-of-life care than those without deaths [14]. Moreover, fewer staff members had difficulties regarding the site of death in facilities with end-of-life care policies, as compared to those in facilities without the policy, as reported by the national survey among nurses working in the long-term care insurance facilities in Japan [15]. Staff members in GHSFs want to support the elderly people until their deaths. However, their facilities often hesitate to undertake end-of-life care because most staff members recognize that it is determined by the role of GHSFs as "intermediate" facilities between hospitals and home [12] [16]. It seems that the establishment of a basic policy regarding sites of death in GHSFs helps staff members realize that end-of-life care forms part of their duties in the facilities and facilitates attitudes geared towards supporting elderly persons until they reach the sites of death in the GHSFs. The position of GHSFs will guide staff members with regard to support for endof-life care provision to elderly persons and their families, instilling a sense of confidence among staff members. Therefore, it is assumed that GHSFs can perform end-of-life care after the establishment of policies regarding sites of death. Miyashita et al. have reported that most Japanese people adopt 10 attitudes towards good deaths- "having good relationships between patients and medical workers or their families", "less burdens on the end-of-life care for their family and relatives", and "spending rest of time at the place which patients want", etc. [17]. As compared to those who did not, elderly persons who often used the services of GHSFs were more likely to choose these facilities as a place of good death. The establishment of a basic policy on end-of-life care would promote the sites of death at GHSFs.

Our results also showed that preparation of preference documents was one of the positive factors associated with the sites of death in GHSFs. Japan Association of GHSFs has reported that only 7.7\% of elderly persons residing at these facilities can independently present their living wills to sites of death by themselves [7]. Ikegami et al. have stated that $39 \%$ of families consult with their elderly residents in nursing homes regarding the living will [11]. In Japan, most families decide on living wills for elderly persons, instead of independent decision-making by the elderly. It has been found that most families preparing living wills for elderly persons experience difficulties. Staff members provide end-of-life care experience difficulties similar to those experienced by the families. Aida has stated that most Japanese people prefer good death, for themselves and others, more than they do decision-making by patients [18]. Thus, the role of documented preferences, as communication tools, is to promote decision making regarding the drawing of living wills by both patients and their families [18]. Our results may suggest that the documentation of preferences enables the elderly persons, their families, and staff at the facilities to prepare for the elderly's deaths and for the remainder of their lives.

We also found that most staff members initially noticed fewer physical signs of pain at the site of death in GHSFs designated as sites of death than those not designated. According to research by Japan Association of GHSFs, the rate of administration of pain control in GHSFs was only 3.0\% [7]. This suggests that GHSFs in Japan do not provide end-of-life care to elderly persons with severe pain. Due to the current increase in the mortality rate of cancer in Japan, GHSFs would have to, in the near future, accept elderly persons with cancer [7]. GHSFs should prepare end-of-life care such as pain control for elderly persons. Moreover, staff at these facili- 
ties should learn the required care skills for people with severe pain. Subsequent to this, GHSFs will request that the government increase the benefits relating to pain control in relation to the long-term care insurance.

There were differences between GHSFs designated as sites of death and those not designated, with regard to the physical signs initially noticed by most staff members. GHSFs designated as sites of death more often identified "reduced oral intake", "sleepiness during daytime", and "less vigor" than did those not designated. On the other hand, GHSFs not designated as sites of death noticed "oliguria", "dyspnea”, "edema”, and "complaints of pain" more frequently than did those designated as sites of death. A previous study on nursing homes with aggressive end-of-life care has reported that end-of-life physical signs include, firstly, reduced oral intake, less vigor, and sleepiness during daytime, and secondly, changes in respiration and the appearance of edema [19]. Our results showed that GHSFs designated as sites of death identified reduced activity levels and behaviors, as opposed to vital signs, as early end-of-life signs. It seems that elderly persons, their families, and staff in GHSFs can prepare for the elderly's death more efficiently, on the basis of findings regarding the early end-of-life period. Lynn has reported that the natural course of death involves prolonged deterioration among elderly persons with dementia and frailty [20]. Our findings suggest that end-of-life triggers often observed in GHSFs designated as sites of death are low activities and behaviors. The doctors and collaborating medical staff in GHSFs should attain more of the relevant skills and observe elderly persons experiencing a gradual decrease in activities.

GHSFs are considered to be some of the helpful facilities providing the long-term care in familiar environments in Japan's comprehensive care system [4]. However, we assumed that the functions, which the GHSFs are requested to specify, differ by residential area. GHSFs have multiple functions in their support of elderly persons during provision of the long-term care. In the near future, the functions of GHSFs may, for example, be divided as follows, according to medical and/or the long-term care resources, and individual characteristics for elderlies: strengthening living functions, facilitating return to home, specializing in end-of-life care, providing care without considering the distinctions between the facilities and the home environment, and providing care to elderly persons with dementia only [4]. This study showed the strengths and characteristics of GHSFs designated as sites of death. GHSFs can observe the deterioration of elderly persons and notice early end-of-life physical signs. In view of this, the facilities presumably manage to provide long-term care through cooperation with elderly persons and their families, and support the former's hope to be taken care of in a home that is near the site of death. Thus, it is suggested that GHSFs function as a hub of end-of-life care networks. It is noteworthy that, of the many deaths occurring in Japan, national policies relating to deaths favor a decrease in the number of deaths in hospitals and an increase in the number of deaths in homes and facilities. Furthermore, we suggest improvement of aspects of the long-term care benefits, because the multiple functions that GHSFs have are great value in sites of death among elderlies.

Our study has some limitations. Firstly, the response rate in our study was only $26.0 \%$, and approximately $80 \%$ of eligible responses were sourced from facilities with sites of death. A previous study on end-of-life care in GHSFs reported that facilities with sites of death made up less than $50 \%$ in all responses [3]. The number of responses from GHSFs designated as sites of death in our study was higher than that in the previous study. Our results may be an underestimate. Secondly, facilities with one or more deaths within the past year were defined as GHSFs designated as sites of death. Facilities with only one death were, therefore, designated as GHSFs designated as sites of death. A detailed analysis by the number of deaths is required, in future. Thirdly, the endof-life period was not defined in our study because we had difficulty to find beginning of sites of death among elderlies. Our results may include differences that staffs feel the beginning of the end-of-life. Fourthly, medical managers described end-of-life physical signs that staff first noticed. These responses may slightly differ from those that staff could have directly reported noticing. Finally, we could not obtain detailed information on documented preferences regarding end-of-life care; examples of lacking details include the dates on which the documents were created and the frequency with which they were revised. Another study may have to assess the influence of documented preferences on end-of-life care, with regard to timing and description of them.

\section{Conclusion}

Our study revealed the characteristics and factors related to end-of-life care in GHSFs across Japan. GHSFs designated as sites of death had more basic policies relating to end-of-life care facilities, as well as documented preferences in the form of a living will than those not designate. These GHSFs were also less likely to identify pain as a first end-of-life physical sign. We suggest that GHSFs identify earlier symptoms, such as reduced oral intake and less vigor, in the end-of-life period, as well as support elderly persons and their families, by improv- 
ing end-of-life care through the implementation of basic policies and those relating to the documentation of preferences. We hope that the strengthening of intermediate facilities would render the role of GHSFs important, in the provision of end-of-life care to elderly persons in Japan.

\section{Acknowledgements}

We are grateful to Mr. Ryou Tachihara for collecting, sorting, and capturing the data. This study was supported by JSPS KAKENHI Grant Number 25463551 (2013-2015).

\section{References}

[1] Cabinet Office, Government of Japan (2013) Annual Report on the Aging Society: 2012, 1-12. (In Japanese)

[2] Tokyo Metropolitan Government (2012) Long-Term Care Insurance System. http://www.fukushihoken,metro,tokyo.jp/kourei/koho/kaigo_pamph.files/kaigohoken-english.pdf

[3] Japan Association of Geriatric Health Service Facilities (2015) What is the Geriatric Health Service Facilities? www.roken.or.jp/wp/abpit_roken (In Japanese)

[4] Nakaura, S., Tochimoto, I. and Higashi, K. (2015) We Think about the Future of Geriatric Health Service Facilities. Rouken, 25, 24-31. (In Japanese)

[5] Ministry of Health, Labor and Welfare (2015) Outline of Change in the Long-Term Care Insurance System for Fiscal Year 2009. www.mhlw.go.jp/bunya/seikatsuhogo/fukusijinzai_kakuho102/dl/04.pdf (In Japanese)

[6] Ministry of Health, Labor and Welfare (2015) Outline of Change in the Long-Term Care Insurance System for Fiscal Year 2012. www.mhlw.go.jp/stf/shingi/2r9852000002113p-att/2r98520000021163.pdf (in Japanese)

[7] Japan Association of Geriatric Health Service Facilities (2012) Report of the End-Of-Life Care as One of Multifunction in the Geriatric Health Service Facilities. (In Japanese)

[8] Hara, S., Ono, M., Ohata, M., Iwagou, S. and Numoto, K. (2010) End-of-Life Care Provided and Emotional Instability Experienced by Care Staff of Elderly Care Facilities. Journal of Japan Society of Nursing Research, 33, 141-149. (In Japanese)

[9] Sasuga, Y., Ushida, T., Kameyama, N. and Turuta, Y. (2006) Present Situation and Future Tasks in End-of-Life Care in the Elderly-From the Results of an Investigation of Nursing Staff Employed at Long-Term Care Insurance Facilities. Journal of Japan Academy of Gerontrological Nursing, 11, 70-78. (In Japanese)

[10] Hiramatsu, M., Obuchi, R. and Kitagawa, A. (2011) A Survey of End-of-Life Care in Geriatric Health Service Facilities-Awareness of Nurses and Care Staffs. Mie Nursing Journal, 13, 147-154. (In Japanese)

[11] Ikegami, N. and Ikezaki, S. (2010) Life Sustaining Treatment at End-Of-Life Care in Japan: Do the Perspectives of the General Public Reflect Those of the Bereaved of Patients Who Had Died in Hospitals? Health Policy, 98, 98-106. http://dx.doi.org/10.1016/j.healthpol.2010.05.016

[12] Ono, M. and Hara, S. (2011) End-of-Life Care Experiences of Care Workers at Geriatric Health Service Facilities. Bulletin of Shimane University Faculty of Medicine, 34, 7-16. (In Japanese)

[13] Ministry of Health, Labor and Welfare (2014) Vital Statistics in Japan: 2013. www.e-stat.go.jp/SG1/estat/html/GL02100101.html (In Japanese)

[14] Ikegami, N. and Ikezaki, S. (2012) Japan's Policy of Promoting End-of-Life Care in Nursing Homes: Impact on Facility and Resident Characteristics Associated with the Site of Death. Health Policy, 105, 303-311. http://dx.doi.org/10.1016/j.healthpol.2012.01.009

[15] Japanese Nursing Association (2013) Nationals Survey Report on the Working Conditions of Nurse in Long-Term Care Insurance Facilities 2013. (In Japanese)

[16] Orii, Y. (2006) A Survey of Awareness of Palliative Care in a Geriatric Intermediate Care Facility in An Urban Area: Compare the Nurse with the Care Worker. Journal of Japan Academy of Gerontrological Nursing, 10, 85-91. (In Japanese)

[17] Miyashita, M., Sanjo, M., Morita, T. and Uchitomi, Y. (2007) Good Death in Cancer Care: A Nationwide Quantitative Study. Annals of Oncology, 18, 1090-1097. http://dx.doi.org/10.1093/annonc/mdm068

[18] Aida, K. (2013) “Good Death” and “Living Well”. HOSPITALS, 72, 275-279. (In Japanese)

[19] Iwase, K. and Katsuno, T. (2013) Signs and Timing of Sings of Nearing Death of the Elderly Sensed by Nurses in Nursing Home That Actively Strive to Give the End-of-Life Care. Journal of Japan Academy of Gerontrological Nursing, 18, 56-63. (In Japanese)

[20] Lynn, J. (2001) Serving Patients Who May Die Soon and Their Families. JAMA, 285, 925-932. http://dx.doi.org/10.1001/jama.285.7.925 